\title{
Desenvolvimento e avaliação de tecnologia educacional sobre administração de vacinas no vasto lateral da coxa
}

Lívia Cristina Scalon da Costa ${ }^{1}$, Lara Aparecida de Freitas ${ }^{2}$, Carolina Costa Valcanti Avelino ${ }^{3}$, Alice Silva Costa ${ }^{4}$, Marcos de Abreu Nery ${ }^{5}$, Sueli Leiko Takamatsu Goyatá ${ }^{6}$

\section{RESUMO}

Desenvolvimento e avaliação de um curso sobre administração de vacinas no vasto lateral da coxa, por meio da Plataforma Moodle. Pesquisa quantitativa, descritiva e transversal, realizada em 2016 e 2017, com 39 estudantes de enfermagem. A Teoria da aprendizagem multimídia e o design instrucional nortearam o desenvolvimento do curso, que contou com três módulos e material de apoio didático, vídeo de cenário simulado, fórum de discussão. O Inquérito COLLES foi utilizado para avaliar a qualidade do AVA; 97,5\% dos graduandos consideraram a formatação, o acesso, a navegação e a imagem "adequado" e "muito adequado". Os itens relevância, reflexão crítica e compreensão obtiveram melhores resultados, segundo o Inquérito COLLES; 92,3\% dos estudantes disseram que gostariam de utilizar o AVA em outras disciplinas. Conclui-se que a tecnologia educacional desenvolvida é uma potente ferramenta para a atualização sobre a temática, visando uma prática segura do futuro profissional enfermeiro nos serviços de saúde.

Descritores: Tecnologia Educacional; Educação em Enfermagem; Vacinas.

\footnotetext{
${ }^{1}$ Enfermeira, Mestre em Enfermagem. Discente do Programa de Pós-Graduação em Ciências da Saúde, nível Doutorado, da Universidade Federal de São Carlos. São João da Boa Vista, SP, Brasil. E-mail: livia.scalon@hotmail.com.

${ }^{2}$ Enfermeira. Discente do Programa de Pós-Graduação em Enfermagem, nível Mestrado, da Universidade Federal de Alfenas. Alfenas, MG, Brasil. Email: larafreitas7@hotmail.com.

${ }^{3}$ Enfermeira, Mestre em Enfermagem. Técnica Administrativa em Educação da Universidade Federal de Alfenas. Alfenas, MG, Brasil. E-mail: ccv89@yahoo.com.br.

${ }^{4}$ Enfermeira. Residente Multiprofissional em Saúde da Família da Universidade Federal de Alfenas. Alfenas, MG, Brasil. E-mail: alicescosta14@gmail.com.

${ }^{5}$ Físico, Doutor em Educação. Técnico em Assuntos Educacionais da Universidade Federal de Alfenas. Alfenas, MG, Brasil. E-mail: marcosnery2009@gmail.com.

${ }^{6}$ Enfermeira, Doutora em Enfermagem Fundamental. Professora Associada da Escola de Enfermagem da Universidade Federal de Alfenas. Alfenas, MG, Brasil. E-mail: sueligoyata@yahoo.com.br.
}

Artigo recebido: 29/11/2017.

Artigo aprovado: 26/09/2018.

Artigo publicado: 31/12/2018.

\section{Como citar esse artigo:}

Costa LCS, Freitas LA, Avelino CCV, Costa AS, Nery MA, Goyatá SLT. Desenvolvimento e avaliação de tecnologia educacional sobre administração de vacinas no vasto lateral da coxa. Rev. Eletr. Enf. [Internet]. 2018 [acesso em: ];20:v20a52. Disponível em: https://doi.org/10.5216/ree.v20.54108. 


\section{INTRODUÇÃO}

A enfermagem tem em sua essência o cuidar. O preparo e a administração de vacinas são considerados uma das principais atribuições desses profissionais, sendo essa realidade vivenciada diariamente na Estratégia Saúde da Família (ESF) e só sendo possível de ser cumprida com efetividade por meio do trabalho em equipe ${ }^{(1)}$.

Além disso, nota-se que a eficácia na administração de imunobiológicos tem relação direta com o conhecimento da equipe de enfermagem sobre a conservação, o preparo e a administração de vacinas. Falhas nesses procedimentos podem ocasionar sérios riscos aos pacientes, como os Eventos Adversos Pós-Vacinação (EAPV), sendo responsabilidade do profissional enfermeiro promover um ambiente seguro para a prática da imunização(2).

Nos dias atuais, verifica-se um aumento significativo no uso do músculo vasto lateral da coxa, sendo o local indicado para a maioria das vacinas intramusculares do calendário básico, sobretudo em crianças menores de dois anos de idade, uma vez que nessa faixa etária é o músculo com maior massa ${ }^{(3-4)}$.

A administração de imunobiológicos é um procedimento complexo e, embora seu conteúdo seja ministrado na graduação de enfermagem e no curso técnico, frequentemente no ensino presencial, a utilização de ferramentas tecnológicas apresenta uma grande variedade de possibilidades e inovações o que pode auxiliar no ensino e na atualização do conhecimento dos futuros profissionais enfermeiros ${ }^{(5)}$.

O avanço tecnológico, na área da saúde inclusive, ocorrido nas últimas décadas, tem levado à necessidade de introduzir inovações não somente no ensino de enfermagem, mas tem transformado o processo de ensinoaprendizagem e apontado uma nova tendência na educação como um todo, por meio do uso crescente de Tecnologias de Informação e Comunicação (TIC) ${ }^{(6)}$.

As TIC podem criar experiências interativas, dinâmicas e multissensoriais, além de um aprendizado mais autônomo, fatores que podem contribuir para a melhoria do processo ensino-aprendizagem ${ }^{(7-8)}$.

Nesse contexto, tem-se o desenvolvimento do Ambiente Virtual de Aprendizagem (AVA), que consiste em sistemas computacionais disponíveis na internet, destinados ao suporte de atividades mediadas pelas TIC. O AVA permite a integração de diversas mídias, linguagens, recursos e atividades, com informações de maneira organizada, o desenvolvimento de interações entre pessoas e objetos de conhecimento e a elaboração e socialização de produções, inovando o ensino da enfermagem ${ }^{(9)}$.

A Plataforma Modular Object-Oriented Dynamic Learning Environment (Moodle) é um dos ambientes de aprendizagem virtuais mais utilizados pelas instituições de ensino superior no Brasil, uma vez que possibilita a simulação de várias situações em sala de aula, a gestão acadêmica dos participantes, a elaboração de relatórios de acesso e atividades, e promove a interação entre alunos e docentes, permitindo, dessa forma, maior autonomia e aquisição de novas habilidades ${ }^{(10)}$.

O Moodle é um software de uso livre, que possibilita aos professores, tutores e alunos trabalharem dentro de um ambiente online de aprendizagem protegido por senha, disponível em mais de 40 idiomas ${ }^{(11)}$. Os professores podem conduzir cursos via internet por meio de sua instituição de ensino ${ }^{(9)}$.

No Moodle, podem ser disponibilizados arquivos de texto, áudio e vídeo, contando com recursos de comunicação síncrona como o chat, no qual os participantes realizam uma discussão entre professores e alunos, 
em tempo real, via Web. Além da comunicação assíncrona, como fóruns de discussão, que permite o debate entre os professores, tutores e alunos; e wikis, que são textos construídos de forma colaborativa ${ }^{(7)}$.

Diante disso, propõe-se utilizar o AVA como recurso de ensino-aprendizagem de graduandos de Enfermagem dos últimos períodos para a administração de vacinas no vasto lateral da coxa em crianças. Esse mecanismo pode propiciar e estimular a atualização do conhecimento e o aprendizado autônomo, o que contribui para uma formação focada em competências e uma maior segurança para o futuro profissional enfermeiro e o paciente na prática clínica, na Atenção Primária à Saúde (APS).

Este estudo teve como objetivo desenvolver e avaliar um curso online sobre administração de vacinas no vasto lateral da coxa, por meio da Plataforma Moodle. Com isso, promover uma atualização sobre a temática para graduandos em enfermagem dos últimos períodos.

\section{MÉTODOS}

Pesquisa quantitativa, descritiva e transversal realizada durante o período de novembro de 2016 a junho de 2017, com 39 graduandos de enfermagem da Universidade Federal de Alfenas (UNIFAL-MG) dos 7으, 8o e 9o períodos e com idade entre 20 a 40 anos.

Como critérios de inclusão foram definidos: graduandos do 7ํ, 8o e 9o períodos de enfermagem, matriculados no 1으 semestre letivo de 2017, independente de sexo e idade, e que concordaram em participar da pesquisa por meio da assinatura do Termo de Consentimento Livre e Esclarecido (TCLE). Já os critérios de exclusão foram: estudantes que, mesmo matriculados no 7ำ, 8o e 9을 período, do primeiro semestre de 2017 , não estavam disponíveis para participar da pesquisa por licença médica, e dependência em outra disciplina do mesmo período, que dificultou a sua participação nos horários destinados à realização da pesquisa. Foram convidados a participar da pesquisa aqueles que atenderam aos critérios de inclusão estabelecidos, sendo que a aceitação ocorreu mediante a leitura e assinatura do TCLE.

Este estudo foi realizado em duas etapas, sendo a primeira atribuída ao desenvolvimento do curso sobre administração de vacinas no vasto lateral da coxa, no AVA, e a segunda destinada à oferta e à avaliação desse curso pelos participantes.

O desenvolvimento do curso baseou-se na Teoria de aprendizagem multimídia ${ }^{(12)}$, a qual afirma que o aprendizado configura-se em um processo de construção, atribuindo aos recursos audiovisuais grande potencial de melhoria para a aprendizagem, por meio do conjunto entre recursos textuais, sonoros e imagéticos ${ }^{(12)}$.

Utilizou-se para o desenvolvimento do curso e de seus recursos midiáticos o processo de design instrucional, que se configura em cinco diferentes fases: análise, na qual são identificados os objetivos educacionais de acordo com os participantes do curso; design, no qual se definem os recursos midiáticos adequados para uma aprendizagem efetiva por meio de uma matriz; desenvolvimento, no qual foram reunidos todos os elementos que foram selecionados ou criados para cada módulo; implementação, em que ocorre verdadeiramente a ação educacional; e, por fim, a avaliação, que deve contar com a análise da qualidade dos conteúdos educacionais e a efetividade da aprendizagem dos participantes ${ }^{(13)}$.

O desenvolvimento dos vídeos se deu por diferentes etapas. Inicialmente, na fase de pré-produção, foi elaborado um roteiro para cada um deles, de acordo com as orientações do Ministério da Saúde ${ }^{(3)}$ quanto à 
atuação do enfermeiro na sala de vacinação. Também utilizou-se a mesma referência em relação à estrutura física, aos equipamentos, aos materiais permanentes, aos mobiliários e aos insumos básicos da sala de vacina, a fim de que o material a ser produzido fosse o mais fidedigno possível ao real. Em seguida foi realizada a filmagem nos cenários simulados produzidos no Laboratório de Habilidades e Comunicação do Curso de Medicina e por fim, a edição dos vídeos foi realizada no estúdio do Centro de Educação Aberta e a Distância (CEAD) da UNIFAL-MG.

Sony Vegas foi a ferramenta utilizada para a edição de vídeos do curso. Ela conta com diversos plug-ins, sendo considerada, dentre os programas de edição, um dos melhores junto do Adobe Premiere. Tem em seu repertório ferramentas profissionais, saída de qualidade e facilidade de operação. Apresenta capacidade para trabalhar em vídeos nas mais diferentes resoluções e ferramentas avançadas diversas. Além disso, o aplicativo permite fazer edições com facilidade, bastando para isso o aprendizado dos controles de edição ${ }^{(14)}$.

Conforme preconizado pelo processo de construção do design instrucional ${ }^{(13)}$, foi elaborada uma matriz de competências cognitivas, atitudinais e de habilidades, a fim de orientar a seleção dos recursos midiáticos adequados para cada objetivo educacional proposto, privilegiando assim o desenvolvimento dessas competências(15).

Os Módulos 1, 2 e 3 contaram com vídeos de cenários simulados. Para o Módulo 3 foi disponibilizado um estudo de caso clínico por meio de um vídeo, seguido por um fórum de discussão. Para as edições dos vídeos de cenários simulados e do vídeo de estudo de caso clínico simulado foi utilizada a ferramenta Sony Vegas.

Após a realização do curso, os alunos avaliaram a formatação, o acesso, a navegação, o hipertexto e as imagens, além dos recursos midiáticos, tempo disponibilizado para realização do curso e se gostariam de utilizar o AVA em outros cursos e disciplinas.

Para a avaliação da qualidade do AVA foi aplicado o Inquérito Constructivist On-Line Learning Environment Survey (COLLES) ${ }^{(16)}$. Trata-se de um instrumento validado para avaliar seis diferentes domínios de cursos desenvolvidos na Plataforma Moodle: relevância, reflexão crítica, interatividade, apoio dos tutores, apoio dos colegas e compreensão.

O Inquérito COLLES tem sido amplamente utilizado ${ }^{(17-18)}$ para a avaliação da Plataforma Moodle pelos estudantes uma vez que ele integra a própria Plataforma como recurso "pesquisa de avaliação".

O estudo foi aprovado pelo Comitê de Ética em Pesquisa da Universidade Federal de Alfenas pelo Parecer no 1.817.683, CAAE: 59543416.8.0000.5142, estando de acordo com as Diretrizes e Normas Regulamentadoras de Pesquisa envolvendo Seres Humanos, Resolução do Conselho Nacional de Saúde no 466/12(19).

\section{RESULTADOS}

A criação dos vídeos precedeu diversas reuniões com os responsáveis pelo CEAD, com o intuito de apresentá-los ao roteiro e ao cenário simulado, no qual os mesmos contribuíram com ideias e indicaram possíveis ajustes no roteiro para que o material fosse mais dinâmico e atraente aos participantes da pesquisa.

Antes da filmagem, ou seja, da produção dos vídeos, realizaram-se diversos ensaios técnicos, resultando em 12 horas de gravação. Na fase final de edição, foram produzidos três vídeos, sendo o primeiro com duração de quatro minutos e 56 segundos, o segundo com quatro minutos e 12 segundos e o terceiro com duração de seis minutos e 45 segundos. 
Dos 39 estudantes, prevaleceu o sexo feminino (87,2\%) e a idade média foi de 24,9 anos.

O curso foi dividido em três módulos, 1) Higienização das mãos em salas de vacinação, 2) Preparo para administração de vacina no vasto lateral da coxa em crianças e 3) Administração da vacina no vasto lateral da coxa em crianças.

Quanto à sua estrutura, conforme demostrado no Mapa de Atividades (Figura 1), há a Biblioteca Virtual, com publicações oficiais sobre atualizações recentes do Calendário Nacional de Vacinação. O espaço Café com Prosa foi utilizado para recados e dúvida

Figura 1: Mapa de atividades (página inicial) do curso.

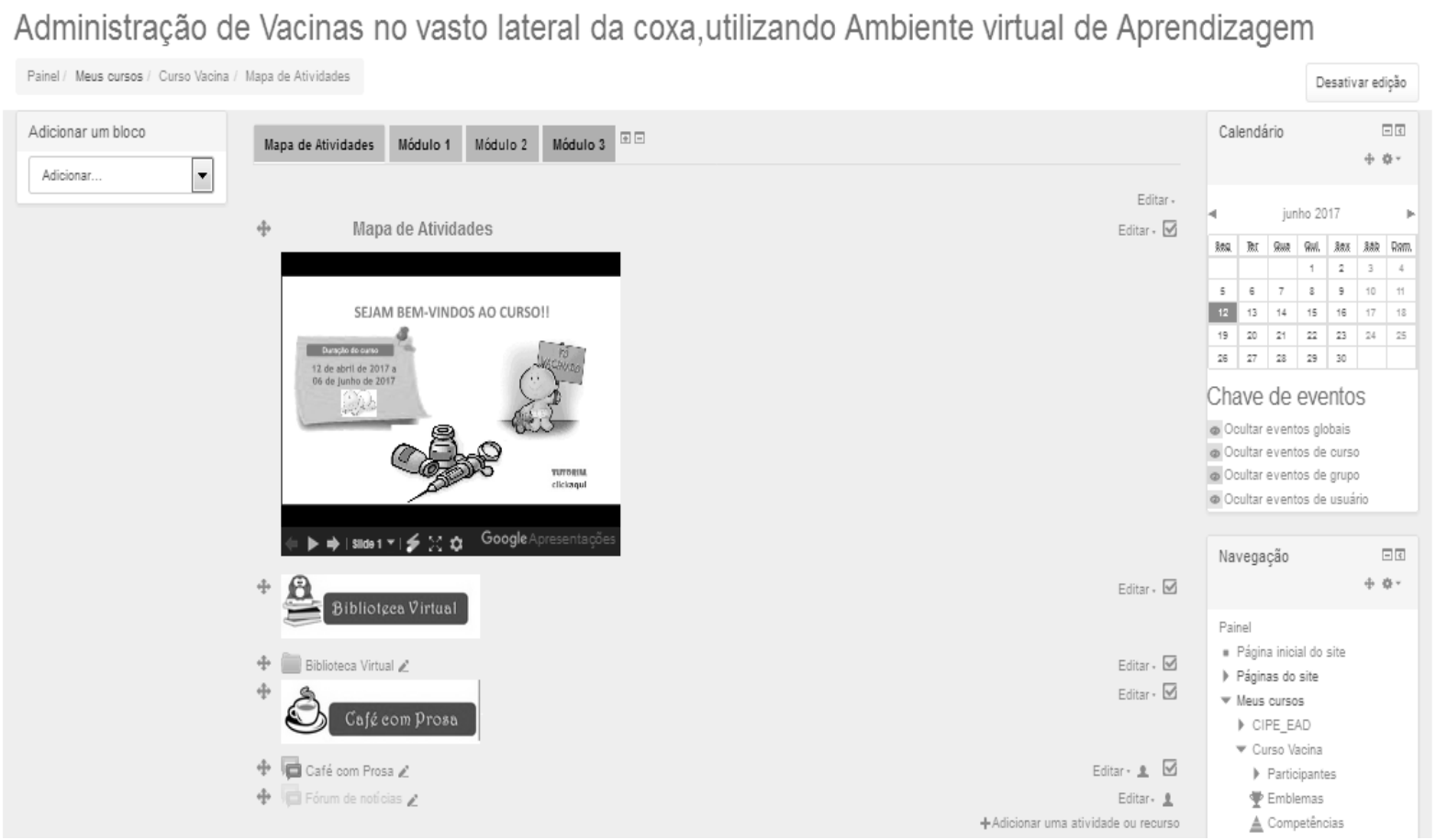

O primeiro módulo teve como conteúdo a perspectiva histórica da higienização das mãos, aspectos microbiológicos da pele e transmissão de patógenos, produtos, equipamentos e insumos necessários para a higienização das mãos, suas finalidades, tipos de técnicas e aquela preconizada para uso na sala de vacinação. 0 segundo módulo teve como foco os cuidados com o acondicionamento e o manuseio de vacinas, as particularidades da remoção e reconstituição de imunobiológicos, uma breve apresentação sobre rede de frio e a apresentação da vacina pentavalente, que foi selecionada para o estudo de caso por conter cinco vacinas.

O terceiro módulo apresenta o músculo vasto lateral da coxa e a técnica de administração de vacina, os EAPV, destacando aqueles principais relacionados à vacina pentavalente, os cuidados com os resíduos da sala de vacinação e o registro da vacina administrada na Caderneta de Saúde da Criança.

Foi elaborado também um tutorial com orientações sobre o curso, como apresentação, dinâmica, acesso e navegação.

Quanto à avaliação do curso pelos participantes, a Tabela 1 apresenta a distribuição percentual sobre a formatação, o acesso, a navegação, os hipertextos e as imagens.

A Tabela 2 apresenta a distribuição percentual dos participantes do estudo na avaliação dos recursos midiáticos utilizados no curso. 
Tabela 1: Distribuição percentual realizada pelos participantes do estudo sobre as características do curso. Alfenas, MG, Brasil, 2017.

\begin{tabular}{|c|c|c|c|c|}
\hline & Inadequado & Pouco Adequado & Adequado & Muito Adequado \\
\hline & $\%(n)$ & $\%(n)$ & $\%(n)$ & $\%(n)$ \\
\hline Formatação & - & $2,5(1)$ & $43,5(17)$ & $54,0(21)$ \\
\hline Acesso & - & $2,5(1)$ & $38,4(15)$ & $59,1(23)$ \\
\hline Navegação & - & $2,5(1)$ & $38,4(15)$ & $59,1(23)$ \\
\hline Hipertextos & $2,5(1)$ & $5,1(2)$ & $35,8(14)$ & $56,6(22)$ \\
\hline Imagens & - & $2,5(1)$ & $33,3(13)$ & $64,2(25)$ \\
\hline
\end{tabular}

Tabela 2: Distribuição percentual da avaliação geral dos recursos midiáticos pelos participantes do curso. Alfenas, MG, Brasil, 2017.

\begin{tabular}{|c|c|c|c|c|}
\hline & Inadequado & Pouco Adequado & Adequado & Muito Adequado \\
\hline & $\%(n)$ & $\%(n)$ & $\%(n)$ & $\%(n)$ \\
\hline Material de apoio didático & - & - & $23,0(9)$ & $77,0(30)$ \\
\hline Vídeo de cenário simulado & - & $2,5(1)$ & $28,2(11)$ & $69,3(27)$ \\
\hline Fórum & - & - & $41,0(16)$ & $59,0(23)$ \\
\hline
\end{tabular}

Todos os módulos apresentavam material de apoio didático que foi elaborado pelos autores, em versão PDF, para que o estudante pudesse realizar o download, salvar o arquivo ou imprimir.

Quanto ao fórum de discussão, houve a utilização de um vídeo de cenário simulado com um estudo de caso clínico, seguido por duas questões disparadoras: questão 1 - "Identifique pelo menos um procedimento realizado de forma inadequada na administração da vacina pentavalente e justifique sua escolha"; e questão 2 - "Agora que você identificou um procedimento realizado de forma inadequada na administração da vacina pentavalente no vasto lateral da coxa, descreva como a técnica deve ser realizada de maneira adequada".

O fórum foi mediado por duas tutoras, as quais realizaram diversas intervenções a fim de aumentar a interação entre os participantes do fórum.

Observou-se que todos os estudantes participaram do fórum de discussão, sendo 75 comentários referentes à questão 1 , com média de 1,92 acessos por participante e 76 comentários referentes à questão 2 , com média de 1,94 acessos por participante.

Quanto ao tempo disponibilizado para a realização do curso, os participantes consideraram: dois $(5,0 \%)$ pouco adequado, $14(35,9 \%)$ adequado e $23(59,1 \%)$ muito adequado.

Em relação ao uso do AVA em outros cursos e disciplinas, 36 (92,3\%) disseram que gostariam de utilizar.

A Tabela 3 apresenta a distribuição percentual das respostas dos participantes do estudo ao Inquérito COLLES- Experiência Efetiva.

Observa-se que os itens relevância, reflexão crítica e compreensão obtiveram melhores resultados, segundo o Inquérito COLLES. Já os itens interatividade e apoio dos colegas foram aqueles que alcançaram os menores percentuais, com respostas "quase nunca" e "raramente". 
Tabela 3: Distribuição percentual das respostas dos participantes ao Inquérito COLLES. Alfenas, MG, Brasil, 2017.

\begin{tabular}{|c|c|c|c|c|c|}
\hline \multirow[t]{2}{*}{ Itens } & $\begin{array}{l}\text { Quase } \\
\text { nunca }\end{array}$ & Raramente & $\begin{array}{l}\text { Algumas } \\
\text { vezes }\end{array}$ & Frequente & $\begin{array}{l}\text { Quase } \\
\text { sempre }\end{array}$ \\
\hline & $f(\%)$ & $f(\%)$ & $f(\%)$ & $f(\%)$ & $f(\%)$ \\
\hline \multicolumn{6}{|l|}{ Relevância } \\
\hline 1. Focalizo em assuntos interessantes. & $2(5,1)$ & - & $6(15,4)$ & $21(53,8)$ & $10(25,7)$ \\
\hline 2. Importante para a prática. & - & - & - & $15(38,3)$ & $24(61,7)$ \\
\hline 3. Melhora meu desempenho. & - & - & $1(2,5)$ & $14(35,8)$ & $24(61,7)$ \\
\hline 4. Tem boas conexões com a minha atividade. & - & - & $1(2,5)$ & $20(51,3)$ & $18(46,2)$ \\
\hline \multicolumn{6}{|l|}{ Reflexão Crítica } \\
\hline 5. Eu critico os conteúdos. & $1(2,5)$ & - & $6(15,4)$ & $22(56,4)$ & $10(25,7)$ \\
\hline 6. Reflito sobre a minha aprendizagem. & - & - & $3(7,9)$ & $21(53,8)$ & $15(38,3)$ \\
\hline 7. Eu critico as minhas próprias ideias. & - & - & $6(15,4)$ & $19(48,8)$ & $14(35,8)$ \\
\hline 8. Eu critico as ideias dos outros participantes. & $1(2,5)$ & $2(5,1)$ & $15(38,3)$ & $16(41,0)$ & $5(13,1)$ \\
\hline \multicolumn{6}{|l|}{ Interatividade } \\
\hline 9. Eu explico as minhas ideias. & $1(2,5)$ & $2(5,1)$ & $17(43,5)$ & $16(41,0)$ & $3(7,9)$ \\
\hline 10. Peço explicações. & - & $2(5,1)$ & $17(43,5)$ & $18(46,3)$ & $2(5,1)$ \\
\hline 11. Me pedem explicações. & $1(2,5)$ & $4(10,2)$ & $15(38,3)$ & $12(30,9)$ & $7(18,1)$ \\
\hline 12. Os participantes reagem às minhas ideias. & $3(7,9)$ & $3(7,9)$ & $21(53,8)$ & $9(22,5)$ & $3(7,9)$ \\
\hline \multicolumn{6}{|l|}{ Apoio dos tutores } \\
\hline 13. Tutor estimula a refletir. & - & $1(2,5)$ & $9(23,0)$ & $21(53,8)$ & $8(20,7)$ \\
\hline 14. Tutor me encoraja. & - & $2(5,1)$ & $5(12,8)$ & $21(53,8)$ & $11(28,3)$ \\
\hline 15. Tutor ajuda a melhorar meu discurso. & - & $1(2,5)$ & $15(38,3)$ & $13(33,5)$ & $10(25,7)$ \\
\hline 16. Tutor ajuda na autocrítica. & $1(2,5)$ & - & $13(33,5)$ & $16(41,0)$ & $9(23,0)$ \\
\hline \multicolumn{6}{|l|}{ Apoio dos colegas } \\
\hline 17. Participantes me elogiam. & $1(2,5)$ & $9(23,0)$ & $21(53,8)$ & $5(12,8)$ & $3(7,9)$ \\
\hline $\begin{array}{l}\text { 18. Participantes estimam as minhas } \\
\text { contribuições. }\end{array}$ & - & $7(18,0)$ & $22(56,4)$ & $6(15,4)$ & $4(10,2)$ \\
\hline 19. Participantes demonstram empatia. & $1(2,5)$ & $7(18,0)$ & $14(35,8)$ & $14(35,8)$ & $3(7,9)$ \\
\hline 20. Participantes me encorajam a participar. & $3(7,9)$ & $7(18,0)$ & $13(33,5)$ & $12(30,4)$ & $4(10,2)$ \\
\hline \multicolumn{6}{|l|}{ Compreensão } \\
\hline 21. Eu compreendo os participantes. & - & - & $7(18,0)$ & $22(56,3)$ & $10(25,7)$ \\
\hline 22.Os participantes me compreendem. & - & - & $16(41,0)$ & $15(38,3)$ & $8(20,7)$ \\
\hline 23. Eu compreendo o tutor. & - & $1(2,5)$ & $4(10,2)$ & $21(53,8)$ & $13(33,5)$ \\
\hline 24. O tutor me compreende. & - & $1(2,5)$ & $8(20,7)$ & $20(51,1)$ & $10(25,7)$ \\
\hline
\end{tabular}

\section{DISCUSSÃO}

O predomínio de estudantes do sexo feminino está em consonância com uma pesquisa semelhante, que evidencia a preponderância de mulheres na carreira de Enfermagem ${ }^{(20)}$. Os resultados desse estudo, que também utilizou a Plataforma Moodle como uma das estratégias pedagógicas em uma unidade de terapia intensiva, evidenciaram que a segurança no preparo dos recursos educacionais permitiu que a associação de diferentes estratégias de ensino, articuladas, preparem os futuros enfermeiros para um desempenho efetivo e eficiente ${ }^{(20)}$.

Em outro estudo realizado ${ }^{(17)}$ que objetivou desenvolver e avaliar um curso na Plataforma Moodle, sobre a Classificação Internacional para a Prática de Enfermagem para graduandos de enfermagem e profissionais enfermeiros, foram encontrados os seguintes dados: $96,1 \%$ consideraram a formatação visual da página adequada, $100 \%$ consideraram o acesso à página da Plataforma Moodle e os hipertextos adequados, $98 \%$ consideraram a navegação na internet e as imagens adequadas. Daí a importância de se utilizar as etapas do design instrucional para tornar a ação educativa mais exitosa, reconhecendo a relevância da avaliação de ferramentas, objetos educacionais, recursos tecnológicos, estrutura, organização, formatação e acesso ao AVA para além da avaliação da própria aprendizagem ${ }^{(13)}$. 
O avanço da web como um espaço de aprendizagem é evidente, o que permite aos estudantes de enfermagem novas formas de comunicação a partir de estratégias pedagógicas inovadoras. O Moodle oferece um número crescente de ferramentas de interação docente-discente, potencializando a construção do conhecimento compartilhado. Ele é um ambiente amigável, de fácil acesso e disponibiliza textos interativos, imagens, gráficos e atividades educativas que favorecem o raciocínio sobre o conteúdo e o desenvolvimento de novas aprendizagens $^{(5)}$.

A utilização dos recursos midiáticos na educação em enfermagem apresenta como principal função oferecer suporte aos alunos para que haja sucesso no processo de ensino-aprendizagem ${ }^{(21)}$. Entre esses recursos, destaca-se o material de apoio didático, que foi mais bem avaliado pelos participantes, contou com a combinação da matriz visual e verbal, organizado em texto e imagem, o que desempenha ainda hoje um papel importante na educação, seja presencial ou a distância ${ }^{(9,13)}$. O material de apoio didático deve contar com aspectos técnicos, gráficos e pedagógicos $^{(17)}$.

Os outros recursos midiáticos utilizados foram o vídeo de cenário simulado e o fórum de discussão. O vídeo é uma mídia extremamente poderosa para atrair e manter a atenção daqueles que o assistem, devido às suas funções de captura, armazenamento, transmissão e apresentação de sons e imagens em movimento, faz com que haja combinação das matrizes sonora, visual e verbal e, também, a facilidade de ofertar conteúdos que seriam difíceis de serem disponibilizados em outros tipos de mídia, como demonstração de situações e habilidades ${ }^{(13)}$.

O uso de recursos audiovisuais e sonoros em ambiente virtual de aprendizagem está ancorado na Teoria de Aprendizagem Multimídia(12) que estabelece três princípios: o pressuposto do canal duplo, no qual o ser humano possui canais de processamento de informação separados (visual e verbal), o da capacidade limitada, ou seja, limitação no processamento de informação em cada canal, e o da aprendizagem ativa, no qual a aprendizagem requer um processamento cognitivo essencial em ambos os canais.

Segundo essa teoria ${ }^{(12)}$, as pessoas aprofundam mais os seus conhecimentos a partir de imagens e palavras do que apenas de palavras isoladas. Se no processo de aprendizagem o conteúdo for construído por meio de palavras e imagens (audição e visão), haverá maior êxito no aprendizado do que se ele focar apenas no sistema de verbalização.

Nota-se que neste estudo, os alunos utilizaram não somente sua capacidade visual, mas também a capacidade sonora, complementando sua capacidade de aprendizado(12-13).

Evidentemente que apenas adicionar imagens a palavras faladas não garantem um êxito educativo. É essencial que a apresentação multimídia seja adequada ao público a que se destina. Para isso, o design instrucional com suas fases, direciona a produção dos recursos midiáticos para o alcance dos objetivos educacionais propostos a um público alvo com perfil definido(13).

Em relação ao fórum, o recurso disparador foi o vídeo de cenário simulado de um caso clínico. Esse recurso, por apresentar uma situação-problema e fatores determinantes para sua resolução, quando disponível em AVA, pode ser enriquecido com áudio, vídeo e/ou animação e conteúdos digitais, conforme foi realizado no presente curso $^{(13)}$. 
O fórum de discussão é uma das ferramentas mais democráticas utilizadas na Plataforma Moodle, onde os alunos têm a liberdade de expor suas opiniões acerca do assunto, postar dúvidas e auxiliar outros participantes, propiciando a interação(22).

O papel dos tutores e professores em cursos online é de instigar as discussões entre os alunos, uma vez que aqueles têm um maior conhecimento sobre a temática que está sendo abordada, sendo também sua atribuição ajudar os estudantes com informações para seu desenvolvimento, com a resolução do problema proposto no fórum e a reconhecer sua capacidade de discussão e de construção de novos conhecimentos com o auxílio dos outros participantes e tutores ${ }^{(22)}$.

Uma das principais características da Educação a Distância é a flexibilização pedagógica, superando os limites de espaço e de tempo por meio do uso de recursos tecnológicos, sendo importante ao planejar um curso nessa modalidade fazer com que o tempo para a sua realização pelos participantes seja adequado aos conteúdos disponíveis e às necessidades dos diferentes sujeitos ${ }^{(23)}$.

Em pesquisa realizada ${ }^{(7)}$ na mesma instituição de ensino junto a 25 estudantes de enfermagem, mostrouse que $92,2 \%$ manifestaram desejo do uso do AVA em outros cursos e disciplinas, fato esse que corrobora os achados do presente estudo.

Em relação ao Inquérito COLLES, pode-se afirmar que foi uma escolha adequada para a avaliação do AVA pelo estudante, uma vez que esse Inquérito monitora práticas de aprendizagem online e verifica em que medida essas práticas são efetivas, do ponto de vista do participante(18).

Assim como na presente pesquisa, em estudo que objetivou avaliar um curso online utilizando a Plataforma Moodle no contexto da educação permanente sobre o aleitamento materno para enfermeiros, os itens melhores avaliados da estratégia por meio do COLLES pelos participantes foram relevância, reflexão crítica e compreensão, sendo os com menores escores a interatividade e o apoio dos colegas ${ }^{(18)}$.

A avaliação da formação em AVA é uma importante ferramenta para a verificação das competências adquiridas pelos estudantes, permitindo identificar quais recursos contribuíram para o resultado final da formação. A Plataforma Moodle oferece diversos módulos que permitem avaliar os diferentes componentes do processo formativo. Nesse contexto, estudos desta natureza são fontes inspiradoras para o uso de novas tecnologias e estratégias de ensino na formação profissional dos futuros enfermeiros.

As transformações pelas quais o mundo todo está passando, com a produção e a incorporação tecnológica, têm resultado em notórios benefícios em diversas áreas, incluindo na enfermagem, apontando a necessidade de readequação dos currículos ${ }^{(24)}$. Porém, para que esses recursos tecnológicos sejam utilizados de forma efetiva, é imprescindível que haja planejamento no desenvolvimento dessas ferramentas e que elas sejam avaliadas, para que possam ser incorporados ao ensino da enfermagem e atender às novas demandas por processos educacionais flexíveis, interativos e que valorizem a autonomia do sujeito aprendiz, inclusive na área de imunização, na qual o papel do enfermeiro é fundamental.

Este estudo apresenta limitação quanto à população estudada, uma vez que foi realizado apenas com estudantes dos últimos períodos do curso de graduação em enfermagem de uma universidade pública federal. Recomenda-se a ampliação da pesquisa para estudantes de outros períodos da mesma instituição e também para 
essa população em universidades privadas, uma vez que o uso do AVA tem sido uma tendência no ensino superior de modo geral.

\section{CONCLUSÃO}

O curso alcançou os objetivos educacionais propostos, visto que a avaliação dos estudantes foi bastante satisfatória, o que vem reforçar a importância do uso de tecnologias educacionais inovadoras na graduação de enfermagem.

Dentre os fatores responsáveis pelo sucesso do curso, destaca-se o planejamento prévio e a aplicação do design instrucional. Quanto aos recursos midiáticos utilizados, todos foram muito bem avaliados, tendo destaques o material de apoio didático e o vídeo de cenário simulado.

Por fim, ressalta-se a importância do Ambiente Virtual de Aprendizagem como estratégia de atualização de competências dos graduandos de enfermagem sobre administração de vacinas no vasto lateral da coxa. Acreditase que essa modalidade de ensino é uma potente ferramenta para a complementação do aprendizado em diferentes temáticas, com vistas a uma prática segura do futuro profissional enfermeiro nos serviços de saúde.

\section{Agradecimentos e financiamentos:}

À Fundação de Amparo à Pesquisa de Minas Gerais-FAPEMIG pela bolsa de Mestrado concedida.

\section{REFERÊNCIAS}

1. Ximenes Neto FRG, Ferreira GB, Ximenes MRG, Bastos EB, Costa SS, Negreiros JA. Necessidades de qualificação, dificuldades e facilidades dos técnicos de enfermagem na Estratégia Saúde da Família. Sanare. 2016; 15(1):47-54.

2. Oliveira VC, Rennó HMS, Santos YR, Rabelo AFG, Gallardo MPS, Pinto IC. Educação para o trabalho em sala de vacina: percepção dos profissionais de enfermagem. R. Enferm. Cent. O. Min. 2016; 6(3):2331-41.

3. Ministério da Saúde. Manual de Normas e Procedimentos para Vacinação. Brasília (Brasil): Ministério da Saúde, 2014. 178p.

4. Hamborsky J, Kroger A, Wolfe S, editors. Centers for Disease Control and Prevention. Epidemiology and Prevention of VaccinePreventable Diseases. 13th ed. Washington: Public Health Foundation; 2015.

5. Salvador PTCO, Martins CCF, Alves KYA, Pereira MS, Santos VEP, Tourinho FSV. Tecnologias no ensino de enfermagem. Rev. baiana enferm. 2015; 29(1):33-41.

6. Landeiro MJSL, Peres HHC, Martins TV. Construção e avaliação de tecnologia educacional interativa para familiares cuidadores sobre cuidar de pessoas dependentes. Rev. Eletr. Enf. [Internet]. 2017 [acesso em 10 nov. 2017]; 19(a13):1-12. Disponível em: http://dx.doi.org/10.5216/ree.v19.38115.

7. Avelino CCV, Costa LCS, Buchhorn SMM, Nogueira DA, Goyatá SLT. Avaliação do ensino-aprendizagem sobre a $\mathrm{CIPE}^{\circledR}$ utilizando o Ambiente Virtual de Aprendizagem. Rev Bras Enferm. 2017; 70(3):630-7.

8. Prado C, Martins CP, Alavarce DC. Ferramentas tecnológicas no ensino de Enfermagem: um universo de possibilidades pedagógicas. In: Prado C, Leite MMJ. Tecnologia da Informação e da Comunicação em Enfermagem. São Paulo: Atheneu; 2011.

9. Bates AWT. Educar na era digital: design, ensino e aprendizagem. 1st ed. São Paulo: Artesanato Educacional; 2016.

10. Sebastião APF. A utilização do Ambiente Virtual de Aprendizagem Moodle em uma Instituição de Ensino Superior Pública. Rev. Profissão Docente. 2015; 15(32):131-9.

11. Szesz Junior A, Silva SCR, Vaz MSMG, Bittencourt DF. Acessibilidade em ambiente virtual de aprendizagem. R. bras. Ens. Ci. Tecnol. 2016; 9(1):1-24.

12. Mayer RE. The Cambridge handbook of multimedia learning. 1st ed. Nova lorque: Cambridge University Press; 2014.

13. Filatro A, Cairo S. Produção de conteúdos educacionais. 1st ed. São Paulo: Saraiva; 2015.

14. Sony Vegas[Internet]. Sony Vegas; 2016 [acesso em: 30 out. 2017]. Disponível em: http://www.sonyvegas.com.br/.

15. Marinho- Araújo CM, Rabelo ML. Avaliação educacional: a abordagem por competências. Avaliação. 2015; 20(2):443-466. 
16. Taylor PC, Maor D. Assessing the efficacy of online teaching with the Constructivist On-Line Learning Environment Survey. In: 9th Annual Teaching Learning Forum - Flexible Futures in Tertiary Teaching, Perth: Curtin University of Technology, 2000 [Internet]. 2000. [acesso em 10 nov. 2017]. Disponível em: http://cleo.murdoch.edu.au/confs/tlf/tlf2000/taylor.html

17. Avelino CCV, Borges FR, Inagaki CM, Nery MA, Goyatá SLT. Desenvolvimento de um curso no Ambiente Virtual de Aprendizagem sobre a CIPE ${ }^{\circledR}$. Acta Paul Enferm. 2016; 29(1):69-76.

18. Freitas LA, Costa LCS, Costa AS, Avelino CCV, Ribeiro PM, Goyatá SLT. Avaliação do curso online na educação permanente sobre aleitamento materno para enfermeiros. Rev Enferm UFSM 2018; 8(1):116-128.

19. Resolução n. 466 do Conselho Nacional de Saúde, de 12 de dezembro de 2012 (BR). Aprova as diretrizes e normas regulamentadoras de pesquisas envolvendo seres humanos. Diário Oficial da União. 12 dez. 2012.

20. Domenico EBL, Cohrs CR. Plataforma Moodle na construção do conhecimento em Terapia Intensiva: estudo experimental. Acta Paul Enferm. 2016; 29(4):381-9.

21. Speroni KS, Vizzott JK. Recursos midiáticos na educação a distância em enfermagem: uma revisão narrativa da literatura. Vidya. 2015; 35(1):41-56.

22. Ferreira AO, Lima CA, Hornink GG. O ensino-aprendizagem online de Bioquímica e as ferramentas de mediação: um estudo de caso. Rev. de Ensino de Bioquímica. 2014; 12(1):1-19.

23. Mill D. Gestão estratégica de sistemas de educação a distância no Brasil e em Portugal: a propósito da flexibilidade educacional. Educ. Soc.. 2015; 36(131):407-426.

24. Gama LN, Tavares CMM. Educação e mídias: implicações contemporâneas no cotidiano acadêmico. Texto Contexto Enferm. 2015; 24(2):593-9. 